J. Nepal Chem. Soc., Vol. 36, 2017

\title{
Electrochemical Behavior of the Composite of Pani/MWCNT Doped with Different Anions
}

\author{
Keshab Koirala and Amar Prasad Yadav* \\ Central Department of Chemistry, Tribhuvan University, Kirtipur, Kathmandu, Nepal \\ Email: amar2y@yahoo.com
}

\begin{abstract}
Polyaniline (PANI) was synthesized from $0.1 \mathrm{M}$ aniline solution dissolved in $0.125 \mathrm{M} \mathrm{H}_{2} \mathrm{SO}_{4}$ solution by chemical oxidative polymerization method using ammonium persulphate as an oxidant. PANI sample was doped with various acids like $\mathrm{HCl}, \mathrm{HNO}_{3}, \mathrm{CH}_{3} \mathrm{COOH}, \mathrm{CHCl}_{2} \mathrm{COOH}$ and composite of various sample of PANI was made with MWCNT by mechanical mixing method. Electrochemical behavior of the composite were studied and analyzed by observing cyclic voltammetry and charge discharge cycle. Conductivity of PANI doped with $\mathrm{HNO}_{3}$ was found to be maximum of $7.1 \times 10^{-2} \mathrm{~S} \mathrm{~cm}^{-1}$. The conductivity of $P A N I$ doped with $\mathrm{H}_{2} \mathrm{SO}_{4}$ prepared at three different temperatures showed that PANI prepared at $10{ }^{\circ} \mathrm{C}$ has highest conductivity in comparison to PANI prepared at other temperature. CV curve showed that the composite of PANI/MWCNT doped with $\mathrm{H}_{2} \mathrm{SO}_{4}$ prepared at $25{ }^{\circ} \mathrm{C}$ has highest specific capacitance value of $532.80 \mathrm{~F} \mathrm{gm}^{-1}$ in comparison to the composite doped with other anions. Composite of PANI doped with $\mathrm{H}_{2} \mathrm{SO}_{4}$ prepared at $50{ }^{\circ} \mathrm{C}$ has highest cyclic stability in comparison to others.
\end{abstract}

Key words: Conducting Polymer, Polyaniline, Carbon nanotubes, Multi walled carbon nanotubes.

\section{Introduction}

\section{Conducting Polymer}

The term polymer is a Greek word meaning many parts. The polymer is made up of many simpler units (molecules having low molecular mass) called monomers, identical to each other or at least chemically similar, joined together in a regular way. Conducting polymers were first discovered in 1976. In the mid-1970s, the first polymer capable of conducting electricity, polyacetylene, was reportedly prepared accidently by Shirakawa ${ }^{1}$.

In 1976, Alan MacDiarmid, Hideki Shirakawa, and Alan Heeger, along with a group of young students found that conductivity of polyacetylene increased by up to 6 orders of magnitude when reacted with iodine (from $10^{-4} \mathrm{~S} \mathrm{~cm}^{-1}$ to $10^{2} \mathrm{~S} \mathrm{~cm}^{-1}$ ); this phenomenon, known as doping, is as a result of charge carriers. In addition, it was discovered that varying the level of doping yielded polymers exhibiting wide range of electrical properties, from insulator, or semi-conductor, to metal ${ }^{3}$. The importance of conducting polymers is exemplified by awarding the Nobel Prize Chemistry in 2000 to MacDiarmid, Shirakawa, and Heeger, for the discovery and development of conducting polymers.

Polymers are known so far as a class of heat sensitive, flexible, electrically insulating amorphous materials, but after the discovery of conducting polymer the scope and application of polymer has been

${ }^{*}$ Corresponding author 


\section{J. Nepal Chem. Soc., Vol. 36, 2017}

widened. These polymers must be doped (usually meaning altering the number of pi electrons) in order to render the polymers truly conducting.

Some recent results indicate that nano engineered conducting polymer composites with carbon nanotubes, which possess a high aspect ratio and high conductivity, may have significantly improved electronic and mechanical properties as compared to pure conducting polymer films.

Electronically Conducting Polymers (ECPs) also called as 'Synthetic Metals' have been the subject of great interest in recent past because of their enormous interesting properties like high electrical conductivity, environmental and chemical stability, low cost, easy synthesis and fast reversible doping and dedoping. Due to their excellent properties they can be used in various applications like in television sets, cellular telephones, automotive dashboard displays an light emitting diodes, polymer artificial cockpit displays, Light Emitting Diodes (LEDs), solar cells, light weight batteries, actuators, corrosion protection agents, sensors and molecular electronic devices, biomedical like tissue engineering scaffolds and supercapacitors.

The most commonly studied classes of conducting polymer were: polyacetylene, polythiophene, polypyrole, polyaniline and derivatives, these polymers being investigated as conducting matrices for electrocatalytic applications ${ }^{5}$. Amongst the family of conducting polymers polyaniline (PANI) is one of the most promising electrically conducting polymers due to its unique electrical, electrochemical properties, high environmental stability and low cost of monomer and ease of synthesis by chemical and electrochemical method of polymerization ${ }^{6}$.

\section{Doping of Polyaniline with Anions}

Non-conductive PANI can be rendered conductive either by acid doping or oxidation. During the doping process, an organic polymer with insulating properties is converted into a polymer approaching metallic conductivity ${ }^{7}$. Doping is the process which converts the neutral polymer backbone to a charged $\pi$ conjugated system. This allows electrons to flow through $\pi$ conjugated system of the conducting polymers due to the formation of conduction bands. Various dopants are used for doping of polyaniline which include $p$-toluene sulphonic acid (PTS), dodecyl benzene sulphonic acid (DBSA), polyvincyl sulfonic acid (PVA), hydrochloric acid, nitric acid, acetic acid, sulphuric acid etc ${ }^{8}$.

\section{Properties of CNT/Polymer Nanocomposites}

Incorporation of Carbon nanotubes (CNT) in polymer matrix resulted in a significant change in mechanical, electrical and thermal properties of polymer matrices. Various factors that influence property modification are processing techniques, type of CNT, aspect ratio and CNT content. It is generally observed that a particular processing method which is good for one property may not be good for another. So it is very important to optimize the various conditions to obtain the nanocomposites with desired properties.

Incorporation of very small amount of CNTs into a polymer matrix can lead to structural materials with significantly high modulus and strength. Significant advancement has been made in improving the mechanical properties of polymer matrix by mixing small fraction of CNTs.

With exceptional mechanical properties, CNTs also possess very high intrinsic electrical conductivity. The electrical conductivity of individual CNTs ranges from $10^{7}$ to $10^{8} \mathrm{~S} \mathrm{~cm}^{-1}$ that is comparable to metals. CNT has helped to impart conductivity in highly insulating material like polymer by fabricating polymer 
nanocomposites. The enhancement in electrical conductivity of insulating polymer by several orders of magnitude has been achieved with a very small loading $(0.021 \mathrm{wt}$ \%) of nanotubes in the polymer matrices.

Thermal properties of a composite are equally important as its mechanical and electrical properties because it gives more freedom in selecting processing conditions and also application area. It is observed that incorporation of CNTs in polymer matrices results in increase of glass transition, melting and thermal decomposition temperatures due to hindered chain and segmental mobility of the polymers.

\section{Experimental Methods}

\section{Materials}

Multi walled carbon nanotubes (MWCNT) (specific surface area $250 \mathrm{~m}^{2} \mathrm{~g}^{-1}$, diameter $10 \mathrm{~nm}$ and length 10-20 $\mu \mathrm{m}$ ) were kindly provided by Baytubes, Bayer AG, Germany. Aniline monomer (molecular wt. 93.13 g., density 1.021 g. $\mathrm{L}^{-1}$ ) was double distilled for the use and chemicals like Ammonium persulphate, $\mathrm{N}, \mathrm{N}$-dimethyl formamide (DMF), $\mathrm{NH}_{3}(14 \mathrm{~N}), \mathrm{HCl}(11.6 \mathrm{~N}), \mathrm{H}_{2} \mathrm{SO}_{4}(36 \mathrm{~N}), \mathrm{HNO}_{3}(16 \mathrm{~N})$, $\mathrm{CH}_{3} \mathrm{COOH}(17.4 \mathrm{~N})$ and $\mathrm{CH}_{2} \mathrm{ClCOOH}$ were used. All these chemicals were of analytical grade.

\section{Preparation of Polyaniline (PANI) by Chemical Oxidation Method.}

- $250 \mathrm{~mL}$. of $0.1 \mathrm{M}$ aniline solution in $0.125 \mathrm{M} \mathrm{H}_{2} \mathrm{SO}_{4}$ solution was prepared.

- $250 \mathrm{~mL}$. of $0.125 \mathrm{M}(\mathrm{NH} 4)_{2} \mathrm{~S}_{2} \mathrm{O}_{8}$ was prepared.

$250 \mathrm{~mL}$. of $0.1 \mathrm{M}$ aniline solution and $250 \mathrm{~mL}$ of $0.125 \mathrm{M}$ ammonium persulphate was prepared and the solutions were kept for $1 \mathrm{hr}$. at room temperature $\left(\sim 20-25^{\circ} \mathrm{C}\right)$, then the two solutions were mixed by dropping ammonium persulphate from burette into aniline solution in a beaker continuously stirring, then the mixture was left over night for polymerization. Next day the resulting dark green PANI precipitate was collected in a filter paper by filtration and was washed with $0.125 \mathrm{M} \mathrm{H}_{2} \mathrm{SO}_{4}$ solution and with acetone. Polyaniline (emeraldine salt) powder was dried in air and then in vacuum at $60{ }^{\circ} \mathrm{C}$. Polyaniline prepared under these reaction and processing conditions are further referred to as "standard" samples. The dried salt sample was kept in air tight plastic bottle. Aniline was polymerized by the above process at three different temperatures; at 10,25 , and $50^{\circ} \mathrm{C}$ so as to prepare three PANI salt samples.

\section{Preparation of Polyaniline (PANI) Base}

The PANI salt sample prepared using the above procedure was dedoped using the large excess of 0.1 $\mathrm{M} \mathrm{NH} 3$ solution to obtain the corresponding base. The $\mathrm{NH}_{3}$ solution containing PANI salt was kept overnight under vigorous stirring and then filtered. The PANI base was air dried and then dried in an oven at about $60^{\circ} \mathrm{C}$ for $72 \mathrm{hrs}$.

\section{Preparation of Polyaniline (PANI) Salt Doped with Different Acids}

The PANI base prepared in the above procedure was powdered and is magnetically stirred in $1.0 \mathrm{M}$ solution of the respective acid for 5-6 hours, left for 24 hours and then filtered, washed and equilibrated with the respective acids in $10^{-2} \mathrm{M}$ concentration and finally filtered and dried.

\section{Preparation of PANI-CNT Composites by Mechanical Mixing Method}

PANI prepared by chemical oxidation method doped with different acids were separately mixed with MWCNT in different ratios (PANI/MWCNT ratios were 1:1 and 4:1) in DMF solvent. The mixture was ultrasonicated for 3-4 hours to disperse the MWCNT bundles and for better incorporation of the MWCNT 
in the polymer matrix. After sonication the mixture was magnetically stirred for 6-7 hours. Finally, the mixture was filtered and washed several times with distilled water and methanol. The PANI/MWCNT composites were collected by drying the powder in vacuum oven at $60{ }^{\circ} \mathrm{C}$ for $24 \mathrm{hrs}$.

\section{Measurement of Electrical Conductivity}

For the measurement of conductivity, $0.047 \mathrm{~g}$. of each composite sample was placed between two iron metal plate and the plates were pressed tightly without touching each other. Then conductivity was measured by two probe multimeter.

\section{Electrochemical Tests}

Various electrochemical properties like electrical conductivity, cyclic voltammetry, and charge discharge cycle of different (PANI/MWCNT) composites were measured.
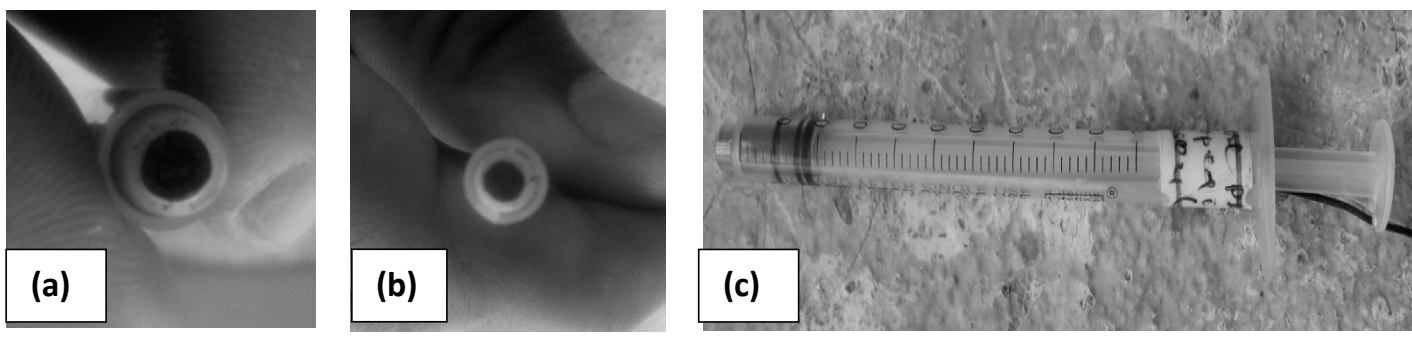

Figure 1: Electrodes of the composite material made on syringe. (a) Doped with $\mathrm{H}_{2} \mathrm{SO}_{4}$ at $25{ }^{\circ} \mathrm{C}$, (b) doped with $\mathrm{H}_{2} \mathrm{SO}_{4}$ at $10^{\circ} \mathrm{C}$ and (c) working electrode made on $3 \mathrm{~mL}$ syringe.

The galvanostatic charge-discharge tests were performed at a current density of $28.58 \mathrm{~mA} \mathrm{~cm}^{-2}$ in the potential window ranging from -1.0 to $1.0 \mathrm{~V}$ in $1 \mathrm{M} \mathrm{H}_{2} \mathrm{SO}_{4}$ solution using three electrodes system.

\section{Results and Discussion}

\section{Measure of Conductivity of Polyaniline Doped with Different Anions}

The conductivity of polyaniline sample doped with different anions was measured using two probe multimeter. Maximum conductivity of $7.1 \times 10^{-2} \mathrm{~S} \mathrm{~cm}^{-1}$ was found the for PANI sample doped with $\mathrm{HNO}_{3}$. This value is many orders of magnitude higher than that of other common polymer which is $10^{-9} \mathrm{~S} \mathrm{~cm}^{-1}$ but lower than that of metals. The conductivity varied with the nature of dopant. This may be due to high degree of protonation or oxidation i.e. doping of PANI with $\mathrm{HNO}_{3}$ introduces large number of charge carrier in the form of extra electrons or holes in comparison to others.

\section{CV of Composite of PANI Doped with Different Anions}

The graph shows that the composite doped with $\mathrm{H}_{2} \mathrm{SO}_{4}$ has good redox current in comparison to others this is probably due to high doping effect of $\mathrm{H}_{2} \mathrm{SO}_{4}$ than others.

The graph shows that the electrochemical behavior of the composite materials depends on the nature of dopant used. 

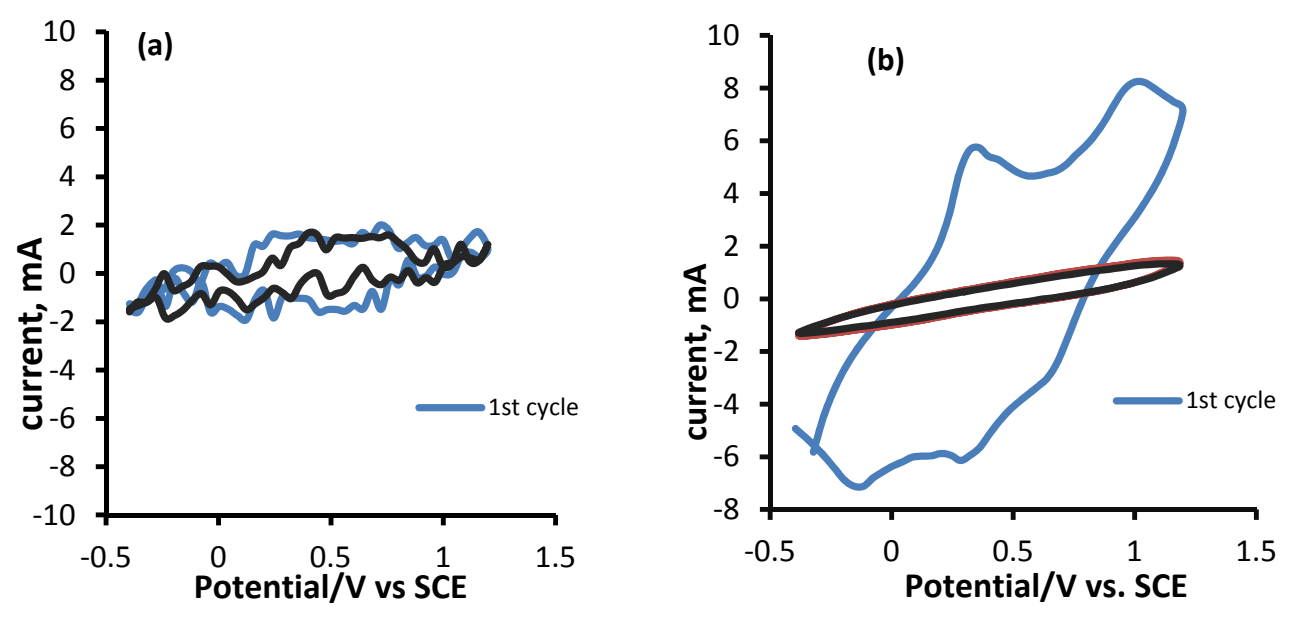

Figure 2: CV of, (a) MWCNT only, (b) PANI only
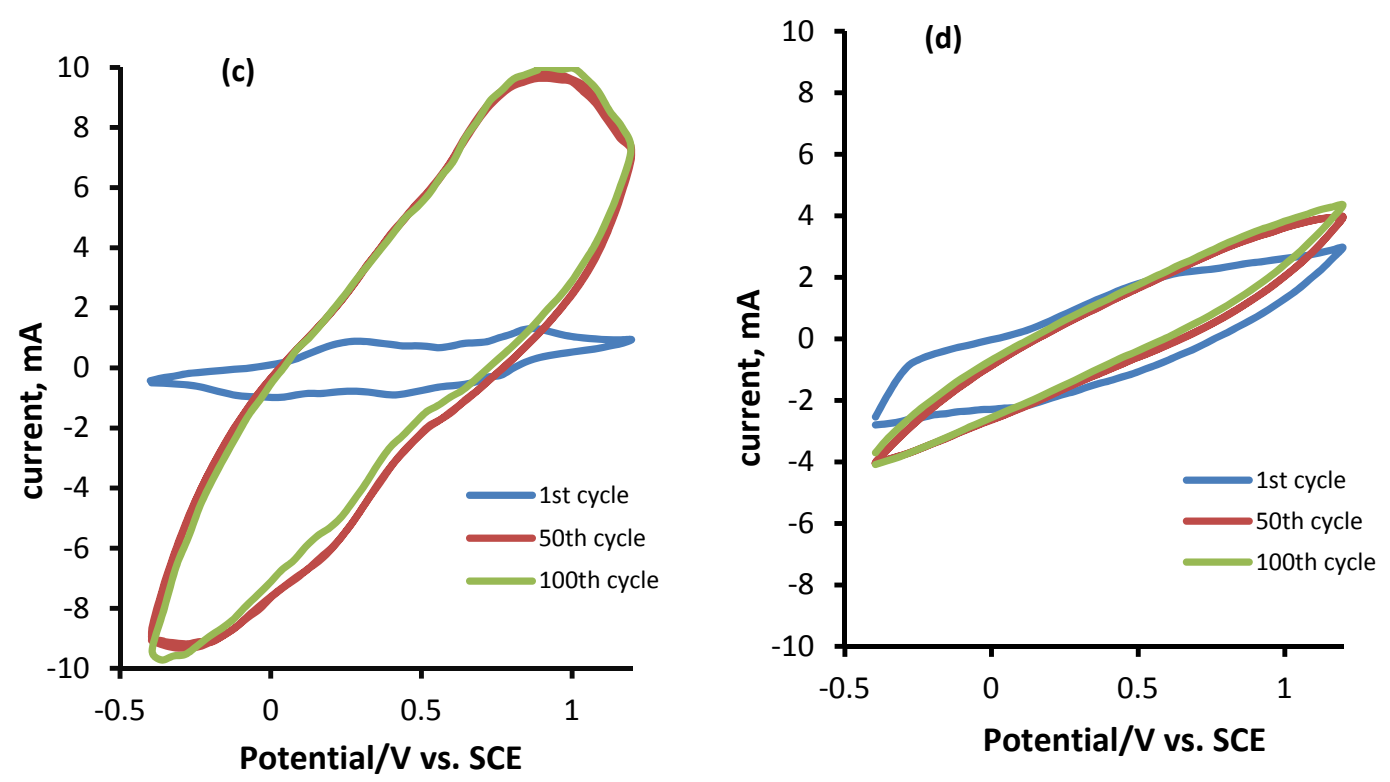

Figure 3: $\mathrm{CV}$ of the composite (doped with different anions), (c) $\mathrm{H}_{2} \mathrm{SO}_{4}$, (d) $\mathrm{HCl}$ 

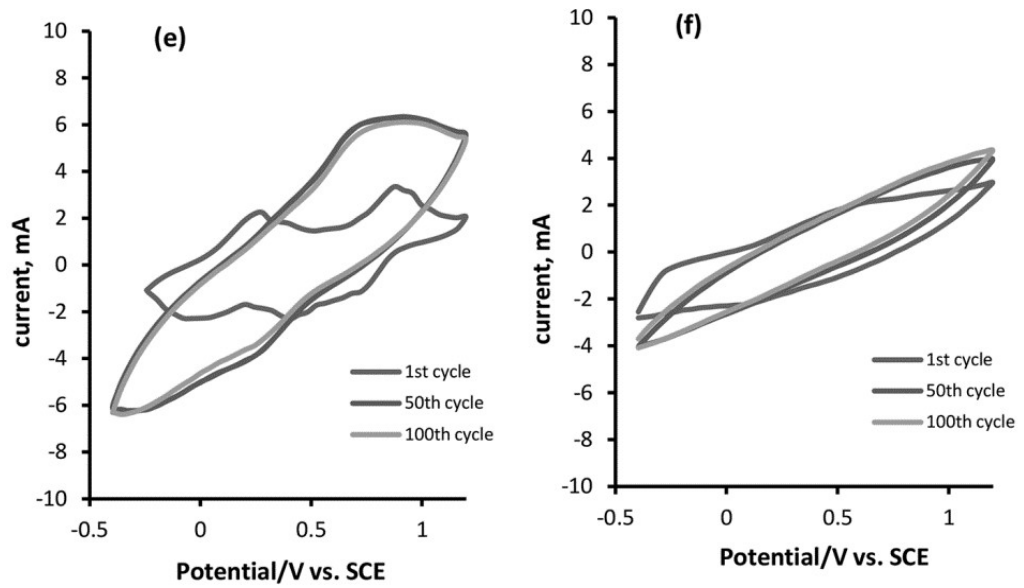

Figure 4: $\mathrm{CV}$ of the composite (doped with different anions), (e) $\mathrm{HNO}_{3},(f) \mathrm{CH}_{3} \mathrm{COOH}$

\section{Capacitive Study}

The capacitive characteristic of the MWCNT, PANI and the PANI/MWCNT composites were investigated by means of cyclic voltammetry.

Capacitance of various composite samples was calculated using the following formula.

Capacitance $(\mathrm{C})=$ Average current $/$ scan rate .

Specific Capacitance $(\mathrm{SC})=$ Capacitance/weight of the active material.

Maximum specific capacitance of $532.80 \mathrm{~F}^{\mathrm{g}} \mathrm{g}^{-1}$ was found for the composite material doped with $\mathrm{H}_{2} \mathrm{SO}_{4}$ prepared at $25^{\circ} \mathrm{C}$.

\section{$\mathrm{CV}$ of Composite (doped with $\mathrm{H}_{2} \mathrm{SO}_{4}$ ) Prepared at Different Temperatures.}

The electrochemical behavior of composite (doped with $\mathrm{H}_{2} \mathrm{SO}_{4}$ ) prepared at three different temperatures 10,25 and $50{ }^{\circ} \mathrm{C}$ was studied by measuring cyclic voltammetry of the composite sample at the scan rate of $50 \mathrm{mV} \mathrm{s}^{-1}$ between the potential ranges of -0.4 to $1.2 \mathrm{~V}$. The sample prepared at $25^{\circ} \mathrm{C}$ has highest current value.

\section{Galvanostatic Charge- Discharge Curve}

The galvanostatic charge discharge cycle of PANI, MWCNT and PANI/MWCNT composites (doped with different anions) at a current density of $28.58 \mathrm{~mA} \mathrm{~cm}{ }^{-2}$ in three electrode system between the potential ranges of -0.1 to $1.0 \mathrm{~V}$ was performed. The $\mathrm{SC}$ of the electrode material is calculated by the following relation,

$$
\text { Specific Capacitance }=(\mathrm{I} \times \Delta \mathrm{t}) /(\Delta \mathrm{V} \times \mathrm{m})
$$

Where, I is charge discharge current, $\Delta \mathrm{t}$ is the discharge time, $\Delta \mathrm{V}$ is the voltage difference $(1.1 \mathrm{~V})$, and $\mathrm{m}$ is the mass of the active composite material $(0.000375 \mathrm{~g})$.

The specific capacitance values of all the composite determined using the galvanostatic charge discharge method followed the trend determined by the $\mathrm{CV}$ measurements. $\mathrm{SC}$ was found to be maximum for the composite material doped with $\mathrm{H}_{2} \mathrm{SO}_{4}$ at room temperature (i.e. $25^{\circ} \mathrm{C}$ ). Here it was observed that 
the SC of MWCNT is less in comparison to the composite of PANI/MWCNT, this enhancement in the $\mathrm{SC}$ of composite may be due to the synergetic effect of MWCNT on PANI.

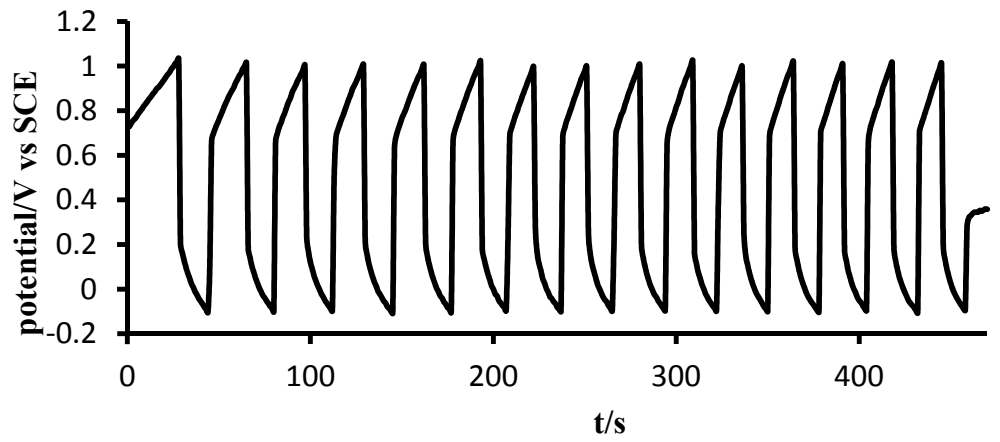

(a)

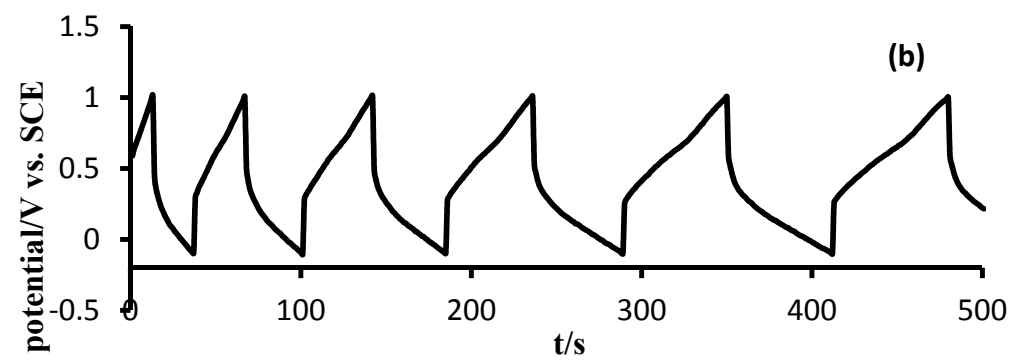

Figure 5: Charge discharge curve of the composite materials. (a) $\mathrm{H}_{2} \mathrm{SO}_{4}$ doped $10{ }^{\circ} \mathrm{C}$. (b) $\mathrm{H}_{2} \mathrm{SO}_{4}$ doped 25 ${ }^{\circ} \mathrm{C}$.

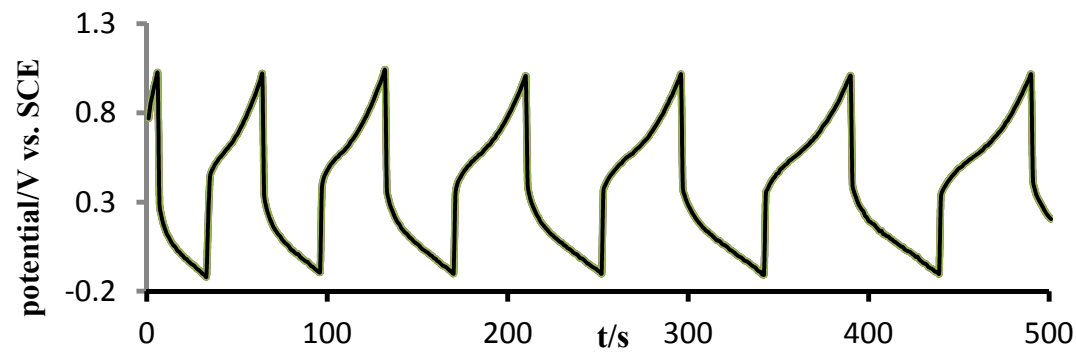

(c)

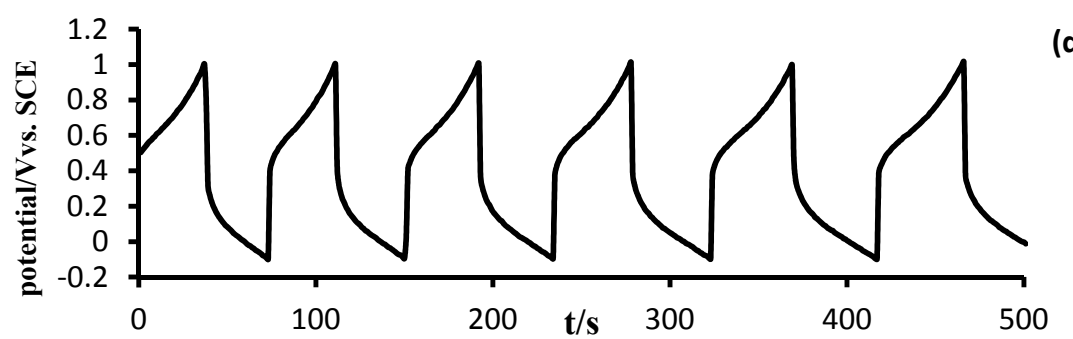

Figure 6: Charge discharge curve of the composite materials, (c) $\mathrm{H}_{2} \mathrm{SO}_{4}$ doped $50{ }^{\circ} \mathrm{C},\left(\right.$ d) $\mathrm{CH}_{2} \mathrm{ClCOOH}$ doped, 

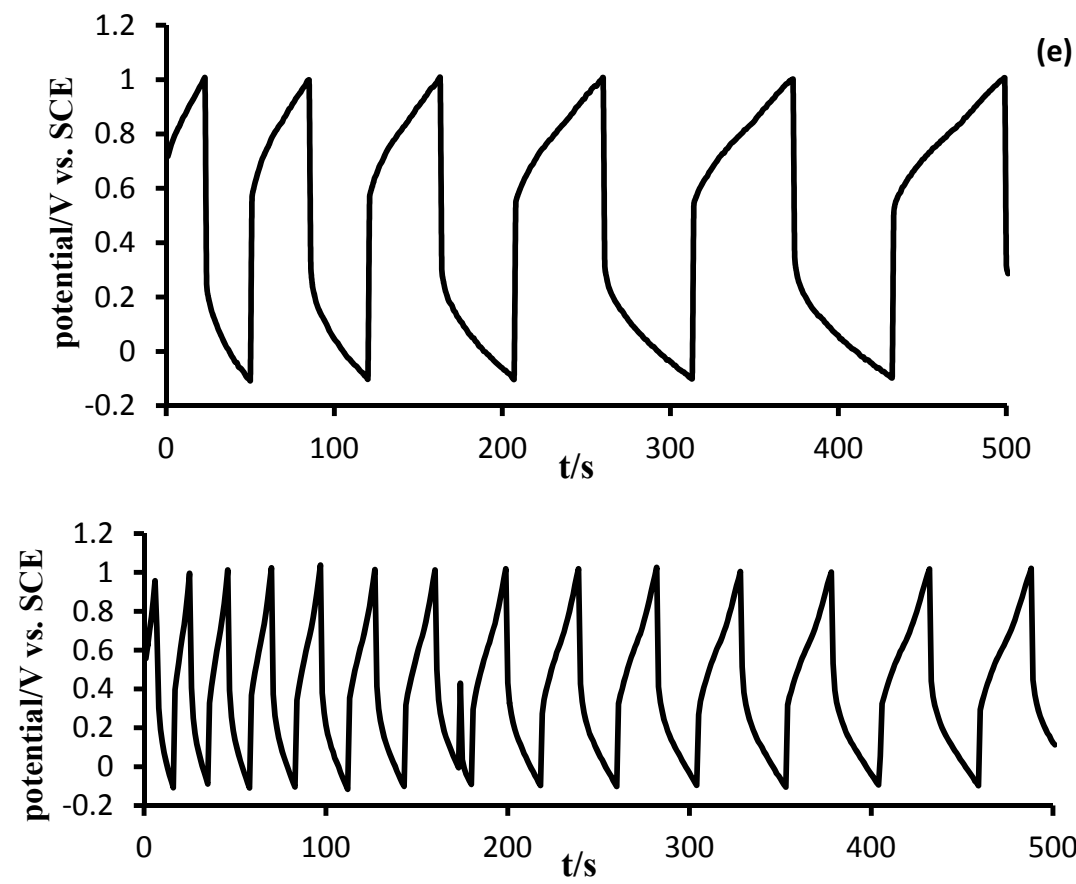

Figure 7: Charge discharge curve of the composite materials. (e) $\mathrm{HCl}$ doped, (f) $\mathrm{HNO}_{3}$ doped

From the study of charge discharge cycle, the PANI doped with $\mathrm{H}_{2} \mathrm{SO}_{4}$ prepared at $25^{\circ} \mathrm{C}$ shows a higher SC, while MWCNT shows less SC value.

\section{Conclusions}

In this work aniline was polymerized by chemical oxidation method by using ammonium persulphate as an oxidant in $0.125 \mathrm{M} \mathrm{H}_{2} \mathrm{SO}_{4}$ solution. The oxidative polymerization of aniline was found to be exothermic in nature. The polyaniline was dedoped with $0.1 \mathrm{M} \mathrm{NH}_{3}$ solution and was again doped with different anions to study the effect of anions on conductivity, specific capacitance and chemical stability of composite materials. Measurements of the conductivity of PANI doped with different anions show that the PANI doped with $\mathrm{HNO}_{3}$ has high conductivity in comparison to the others. Composite materials were prepared by mixing PANI with MWCNT by mechanical mixing method. The specific capacitance for the composite (doped with $\mathrm{H}_{2} \mathrm{SO}_{4}$ at $25{ }^{\circ} \mathrm{C}$ ) has highest values of $532.80 \mathrm{~F} . \mathrm{g}^{-1}$ obtained from CV; this may be due to formation of more active sites over the surface of composite material in comparison to others. The charge discharge curve shows a regular symmetric charging and discharging line which explains good reversible nature of the composite material. The specific capacitance values for composite materials calculated from charge discharge curve have same trend as those calculated from CV curve. Study of CV curve shows that the composite of PANI doped with $\mathrm{H}_{2} \mathrm{SO}_{4}$ prepared at $50^{\circ} \mathrm{C}$ has highest stability in comparison to others. However the composite (doped with $\mathrm{H}_{2} \mathrm{SO}_{4}$ at $25^{\circ} \mathrm{C}$ ) highest redox current (highest SC) and has stability slightly less than the composite (doped with $\mathrm{H}_{2} \mathrm{SO}_{4}$ at $50{ }^{\circ} \mathrm{C}$ ). Thus, of all the materials studied composite of PANI (doped with $\mathrm{H}_{2} \mathrm{SO}_{4}$ at $25{ }^{\circ} \mathrm{C}$ )/MWCNT could be the best material for supercapacitor application. 


\section{Acknowledgements}

The authors are thankful to the university grants commission for financial support and Head of the Central Department of Chemistry, Tribhuvan University, Kathmandu, Nepal for providing the available research facilities to conduct this research work.

\section{References}

1. R. Faez, I. M. Martin, M. A. De Paoli, M. C. Rezedene, Synth. Met., 2001, 119, 435-447.

2. H. Shirakawa,. J. Louis E, A. G. MacDiarmid, C. K. Chiang, A. Heeger, J. Chem. Commun., 1977, 3, 578586.

3. M. S. Ram, P. Srinivasan, Journal of Molecular Catalysis, 2003, 26, 201, 289.

4. A. K. Sharma, Y. Sharmab, S. Gandhi, An International Journal Universal Research Publications, 2012, 63, 598-306.

5. Olgun Gu" ven, Radiation Physics and Chemistry, 2007, 76, 1302-1307.

6. P. D. Gaikwad, D. J. Shirale, V. K. Gade, P. A. Savale, K. P. Kakde, H. J. Kharat, M. D. Shirsat, Bull. Mat. Sci. 2006, 29, 417-420. 